\title{
Genetic Predictive Scores in Heart Failure: Possibilities and Expectations
}

\section{Alexander E Berezin*}

Consultant of Therapeutic Unit, Internal Medicine Department, State Medical University of Zaporozhye, Mayakovsky av, Zaporozhye, UA-69035, Ukraine

\begin{abstract}
Heart failure (HF) remains a major health problem worldwide. Currently used HF risk prediction scores based on clinical findings, echocardiography features, biomarkers cannot propose an individualized approach to risk stratification, whereas there is variability in predictive value of different scores amongst patients with various HF phenotypes. The editorial commentary is devoted the role of the genetic risk prediction scores in the predisposition of HF development and assay in the HF medical care response. The brand new risk scores reflecting variabilities in genetic and epigenetic features in HF development are discussed also.
\end{abstract}

Keywords: Heart failure; Phenotypes; Genetics; Epigenetics; Prediction; Scores

\section{Introduction}

Heart failure remains a global health and social problem associated with a higher risk of cardiovascular (CV) death and enormous economic burden [1]. Although HF is considered a final pathophysiological stage of any CV disease, the development of several HF phenotypes, i.e., HF with reduced ejection fraction (HFrEF), HF with mid-regional ejection fraction (HFmrEF) and HF with preserved ejection fraction (HFpEF), might be resulted in some distinguishes in etiology, the prevalence of $\mathrm{CV}$ risk factors, and co-existing comorbidities, which in particularly impact on nature evolution of the disease [2,3]. Nevertheless, it turns out that prognosis and clinical outcomes of HF phenotypes could be similar and frequently does not closely relate to clinical features, echocardiographic predictors, and biochemical markers' presentation including natriuretic peptides, circulating galectin-3, troponins, and soluble ST2 [4-7]. Moreover, there is large body of evidence regarding that the clinical profile of HF patients who distinguishes 30-day and 1 -year mortality and morbidity might bear a strictly similarity and staggering resemblance [8].

The recent clinical studies have shown that inherited forms of cardiomyopathies have a substantial genetic component, which predisposes to the development of several phenotypes of HF [9-11]. By now, genetic testing has incorporated as a part of patient evaluation for suspected inherited cardiomyopathies [10,11]. However, it turns out the epigenetic modifications through DNA methylation, ATPdependent chromatin remodeling, histone modifications with an involvement of microRNA-related mechanisms might be sufficient pathophysiological factors contributing to adverse cardiac remodeling and altered cardiac function [12]. In this context, the novel risk scores reflecting variabilities in genetic and epigenetic features in HF development appear to be promised [13-15].

Indeed, some early studies have reported interested results with respect togeneticprecursors ofHFpEFandHFrEF [16-22]. Asbiomarkers particularly used to scrutiny single nucleotide polymorphisms (SNPs) of genes encoding enzymes related to oxidative stress [16], genotype of guanine nucleotide-binding proteins (G-proteins) $\beta-3$ subunit (GNB3) [17], transcription factor Islet-1 gene [18], troponin T [19], CYP2D6 polymorphism [20], cardiac myosin binding protein-C mutations [19], renin-angiotensin-aldosterone system polymorphism [21] etc. Indeed, it is well known that angiotensin-converting enzyme (ACE) I/D gene $\mathrm{D}$ allele was associated with higher overall mortality as compared with the I allele in HF patients and that the effect could be modified by ACE inhibitors' given [22]. Additionally, ACE DD and angiotensin- 1-receptor 1166 CC genotypes may synergistically increase the predisposition to HFpEF [23]

Unfortunately, in ARIC (Atherosclerosis Risk in Communities) study was reported that none of the metabolite SNPs including pyroglutamine, dihydroxy docosatrienoic acid were individually associated with incident HF, whereas a genetic risk score created by summing the most sufficient risk alleles from each metabolite determined 11\% greater risk of HF per allele [24]. Ganna et al., (2013) [25] have reported that amongst 707 common SNPs associated with 125 diseases including HF it would not be easily obtained explainable results by common genetic variants related to HF development. Consequently, a close gene-gene interaction may determine an individual risk to development of HF through different pathways including epigenetic modifications. All these findings lead to assume that genes score might be a powerful tool for prediction of HF development.

More successful genome-wide linkage studies toward genes-related contribution in HF have been devoted incorporating SNPs of several genes (i.e., the bradykinin type 1 receptor gene, angiotensin-II type I receptor gene, the $\beta 1$-adrenoceptor gene and CYP2D6 polymorphism) in predictive score to benefit and suffer harm from HF therapy. Although these parmacogenetic studies have focused on promised topics, the obtained results have not been absolutely consistent [26,27]. Nelveg-Kristensen et al, (2015) [27] have found no sufficient association between pharmacogenetic scores and fatal outcomes in HF patients. In contrast, Bondar et al., (2014) [28] have guessed that the gene expression profiling might be useful rather for risk prediction in HF than for choosing HF treatment regime. Thus, the clinical implementation of the HF therapy based on genes scoring remains uncertain and requires more evaluation in the future [29].

*Corresponding author: AlexanderE Berezin, Professor, Consultant of Therapeutic Unit, Internal Medicine Department, State Medical University of Zaporozhye Mayakovsky av, Zaporozhye, UA-69035, Ukraine, Tel: +380612894585; E-mail: dr_berezin@mail.ru; aeberezin@gmail.com

Received October 10, 2016; Accepted October 12, 2016; Published October 14 2016

Citation: Berezin AE (2016) Genetic Predictive Scores in Heart Failure: Possibilities and Expectations. J Data Mining Genomics Proteomics 7: e127. doi: 10.4172/2153-0602.1000e127

Copyright: () 2016 Berezin AE. This is an open-access article distributed unde the terms of the Creative Commons Attribution License, which permits unrestricted use, distribution, and reproduction in any medium, provided the original author and source are credited. 


\section{Conclusion}

Gene-gene interrelations encompass several mechanisms involved into HF phenotype development. The results of the recent genomewide linkage studies have improved our understanding of the role of genetics and epigenetics in the HF progression, whereas the predictive value of genes-based scoring remain controversial especially amongst patients who are not referred as inhered cardiomyopathy individuals. However, prospective randomized clinical trials are required to more pretty accurate explain the predictive role of the genetic risk scores in HF development and response of the HF medical care.

\section{Conflict of Interests}

No significant financial conflicts of interest relevant to the article topic is declared.

\section{Reference}

1. Mozaffarian D, Benjamin EJ, Go AS, Arnett DK, Blaha MJ, et al. (2016) American Heart Association Statistics Committee; Stroke Statistics Subcommittee. Heart Disease and Stroke Statistics-2016 Update: A Report From the American Heart Association. Circulation 133: e38-360.

2. Yancy CW, Jessup M, Bozkurt B, Butler J, Casey DE Jr, et al. (2013) ACCF/ AHA guideline for the management of heart failure: executive summary: a report of the American College of Cardiology Foundation/American Heart Association Task Force on practice guidelines. Circulation 128: 1810-1852.

3. Ponikowski P, Voors AA, Anker SD, Bueno H, Cleland JG, et al. (2016) Authors/ Task Force Members; Document Reviewers. 2016 ESC Guidelines for the diagnosis and treatment of acute and chronic heart failure: The Task Force for the diagnosis and treatment of acute and chronic heart failure of the European Society of Cardiology (ESC). Developed with the special contribution of the Heart Failure Association (HFA) of the ESC. Eur J Heart Fail 18:891-975.

4. Berezin AE, Kremzer AA, Martovitskaya YV, Berezina TA, Gromenko EA (2016) Pattern of endothelial progenitor cells and apoptotic endothelial cell-derived microparticles in chronic heart failure patients with preserved and reduced left ventricular ejection fraction. EBioMedicine 4: 86-94

5. Rocha BM, Menezes Falcao L (2016) Acute decompensated heart failure (ADHF): A comprehensive contemporary review on preventing early readmissions and postdischarge death. Int J Cardiol 223: 1035-1044.

6. Obokata M, Takeuchi M, Negishi K, Ohte N, Izumo M, et al. (2016) Relation Between Echocardiogram-Based Cardiac Parameters and Outcome in Heart Failure With Preserved and Reduced Ejection Fraction. Am J Cardiol S00029149: 31330-31333.

7. Berezin A (2016) Metabolomics in Heart Failure Patients: Hype and Hope. Biomarkers J 2: e21-e23

8. MacDonald MR, Wee PP, Cao Y, Yang DM, Lee S, et al (2016) Comparison of Characteristics and Outcomes of Heart Failure Patients With Preserved Versus Reduced Ejection Fraction in a Multiethnic Southeast Asian Cohort. Am J Cardiol 118: 1233-1238.

9. Teekakirikul P, Kelly MA, Rehm HL, Lakdawala NK, Funke BH (2013) Inherited cardiomyopathies: molecular genetics and clinical genetic testing in the postgenomic era. The Journal of Molecular Diagnostics 15: 158-170.

10. Teo LY, Moran RT, Tang WH (2015) Evolving Approaches to Genetic Evaluation of Specific Cardiomyopathies. Curr Heart Fail Rep 12: 339-349.

11. Hershberger RE, Siegfried JD (2011) Update 2011: clinical and genetic issues in familial dilated cardiomyopathy. J Am Coll Cardiol 57: 1641-1649.

12. Berezin A (2016) Epigenetics in heart failure phenotypes. BBA Clinical 6: 31-37.

13. Yang J, Xu WW, Hu SJ (2015) Heart failure: advanced development in genetics and epigenetics. Biomed Res Int 2015: 352734.
14. Lopes LR, Elliott PM (2013) Genetics of heart failure. BBA Molecular Basis of Disease 1832: 2451-2461.

15. Berezin AE (2016) Epigenetically Modified Endothelial Progenitor Cells in Heart Failure. J Clin Epigenet 2: 21-23.

16. Fazakas A, Szelenyi Z, Szenasi G, Nyiro G, Szabo PM, et al (2016) Genetic predisposition in patients with hypertension and normal ejection fraction to oxidative stress. J Am Soc Hypertens 10: 124-132.

17. McNamara DM, Taylor AL, Tam SW, Worcel M, Yancy CW, et al (2014) G-protein beta-3 subunit genotype predicts enhanced benefit of fixed-dose isosorbide dinitrate and hydralazine: results of A-HeFT. JACC Heart Fail 2: 551-557.

18. Friedrich FW, Dilanian G, Khattar P, Juhr D, Gueneau L, et al. (2013) A novel genetic variant in the transcription factor Islet-1 exerts gain of function on myocyte enhancer factor 2C promoter activity. Eur J Heart Fail 15: 267-276.

19. Hofman N, van Langen I, Wilde AAM (2010) Genetic testing in cardiovascular diseases. Current Opinion in Cardiology 25: 243-248.

20. Sutter ME, Gaedigk A, Albertson TE, Southard J, Owen KP, et al. (2013) Polymorphisms in CYP2D6 may predict methamphetamine related heart failure. Clin Toxicol 51: 540-544.

21. Kolder IC, Michels M, Christiaans I, Ten Cate FJ, Majoor-Krakauer D, et al (2012) The role of renin-angiotensin-aldosterone system polymorphisms in phenotypic expression of MYBPC3-related hypertrophic cardiomyopathy. Eur J Hum Genet 20: 1071-1077.

22. Wu CK, Luo JL, Tsai CT, Huang YT, Cheng CL, et al. (2010) Demonstrating the pharmacogenetic effects of angiotensin-converting enzyme inhibitors on longterm prognosis of diastolic heart failure. Pharmacogenomics J 10: 46-53.

23. Wu CK, Luo JL, Wu XM, Tsai CT, Lin JW, et al. (2009) A propensity scorebased case-control study of renin-angiotensin system gene polymorphisms and diastolic heart failure. Atherosclerosis 205: 497-502.

24. Yu B, Zheng Y, Alexander D, Manolio TA, Alonso A, et al. (2013) Genome-wide association study of a heart failure related metabolomic profile among African Americans in the Atherosclerosis Risk in Communities (ARIC) study. Genet Epidemiol 37: 840-845.

25. Ganna A, Rivadeneira F, Hofman A, Uitterlinden AG, Magnusson PK, et al (2013) Genetic determinants of mortality. Can findings from genome-wide association studies explain variation in human mortality? Hum Genet 132: 553561

26. Yip VL, Pirmohamed M (2013) Expanding role of pharmacogenomics in the management of cardiovascular disorders. Am J Cardiovasc Drugs 13: 151-162.

27. Kristensen KE, Madsen MB, Pedersen TC, Kober L, Egfjord M, et al. (2015) Pharmacogenetic Risk Stratification in Angiotensin-Converting Enzyme Inhibitor-Treated Patients with Congestive Heart Failure: A Retrospective Cohort Study. PLoS One 10: e0144195

28. Bondar G, Cadeiras M, Wisniewski N, Maque J, Chittoor J, et al. (2014) Comparison of whole blood and peripheral blood mononuclear cell gene expression for evaluation of the perioperative inflammatory response in patients with advanced heart failure. PLOS ONE 9: e115097.

29. Berezin AE, Kremzer AA, Martovitskaya YV, Samura TA, Berezina TA, et al. (2015) The utility of biomarker risk prediction score in patients with chronic heart failure. Int J Clin Exp Med 8: 18255-18264. 